\title{
VII. Report of a lecture on the chemistry of geology, delivered at one of the evening meetings at the university of London
}

Edward Turner M.D. F.R.S. L. \& E. Sec. G.S.

To cite this article: Edward Turner M.D. F.R.S. L. \& E. Sec. G.S. (1833) VII. Report of a lecture on the chemistry of geology, delivered at one of the evening meetings at the university of London, Philosophical Magazine Series 3, 3:13, 21-28, DOI: $10.1080 / 14786443308648110$

To link to this article: http://dx.doi.org/10.1080/14786443308648110

曲 Published online: 01 Jun 2009.

Submit your article to this journal $₫$

Џll Article views: 2

Q View related articles $\square$ 


\section{[ 21$]$}

VII. Report of a Lecture on the Chemistry of Geology, delivered at one of the Evening Meetings at the University of London*, by Edward Turner, M.D. F.R.S. L.\& E., Sec. G.S.†

THE lecturer began by explaining that under the title "Chemistry of Geology," he included all those geological phænomena to the elucidation of which chemical principles were applicable. The subject, he said, was one of great extent. He might proceed to consider the affinities which operated in forming the crystalline rocks of the non-fossiliferous series, - to develope the several theories by which it is attempted to account for volcanic action, - to show by what means the soft materials of aqueous deposites were converted into solid rocks, - to trace the effects of heat in modifying the appearance and nature of previously consolidated masses, - to endeavour to explain the origin of mineral waters, - and speculate on the obscure subject of the formation of veins. But he would not then venture to discuss any of those topics, the rather as some of them were then under investigation. He meant to confine his remarks to two parts of the subject: First, to the causes which give rise to the degradation of rocks, thereby providing the materials for new by the destruction of preexisting geological formations ; and, secondly, to the production, by means of aqueous solution, of siliceous and other deposites which were commonly regarded as insoluble. $\mathrm{He}$ would touch cursorily on the former, chiefly with a view to facilitate the comprehension of the latter.

I. Disintegration of Rocks. - The principal agents concerned in the degradation of rocks might, it was said, be conveniently arranged under three heads :-

1. Mechanical agents; such as rain, rivers, and torrents, or, generally, water in motion.-This subject, the lecturer said, did not require comment on that occasion, as it was not only familiar to geologists, but foreign to the plan of his lecture.

2. The alternate congelation and liquefaction of water.-In all situations liable to alternate frost and thaw, this was a most fertile source of destruction to rocks.

Water, insinuating itself into fissures or between the strata of rocks, and congealing there, tore asunder the firmest masses by the immensely expansive force which water exerts in freezing, kept together the disjointed parts, as by cement, while it

- See Lond. and Edinb. Phil. Mag. for June, page 479.

+ The interest as well as the length of this report have induced us to prefer giving it its present place, to inserting it in our "Proceedings of Learned Societies."-EDir. 
remained solid, and on thawing left them to fall asunder by the mere force of gravity. This was perhaps the most influential cause of the vast ruin daily witnessed in the valleys of Switzerland, and in all countries where high mountain chains are intersected by deep narrow gorges, bounded by bare, precipitous, and irregularly fissured escarpments. By the operation of the same cause buildings were defaced and destroyed. When water froze within the cavities of porous stones, the particles were frequently more or less disunited from each other, and crumbled to dust at the first thaw. Building materials differed in their destructibility by frost. The compact tenacious sandstone of Edinburgh suffered little; while some of the handsome colleges of Oxford gave melancholy proof of the injury which it might occasion in the more porous and less tenacious oolite of that county. The lecturer observed, that a scientific knowledge of the cause of such decay had led to the suggestion of a ready mode of estimating the durability, as far as frost was concerned, of different building materials. The freezing of water was a process of crystallization attended, as in most other cases, with forcible increase of volume. The crystallization of salts was a similar phænomenon, and gave rise to a similar effect. "When a stone was dipped into a saline solution, and then suspended in the air to dry, the crystallization of the salt produced a certain amount of injury; and the effect due to one operation might be multiplied to any extent by repetition of the same process. The experiment of a few days might thus be made to imitate the effect of numerous winters, and the relative durability of different materials be ascertained prior to their selection for building. The salt most applicable to such purposes was found to be sulphate of soda*.

3. Chemical Action. - The affinities which principally contribute to affect the integrity of rocks were stated to be those of water and carbonic acid for potash and soda, and that of oxygen for iron. The changes referred to were frequent in felspathic rocks, and were exemplified in a very striking manner in the formation of porcelain clay from granite and other allied rocks rich in felspar. All granitic regions presented examples of this nature, and in none were they more remarkable than in Cornwall and Auvergne. It was probable that the long-continued action of pure water might produce decomposition; but the effect of its affinity for the alkalies of the rock was materially aided by that of carbonic acid for the same bases. This was shown by the increased decomposing power of water when charged with carbonic acid, and by the action

* M. Brard in Ann. de Chim. et de Phys., vol. xxxviii. p. 160. 
of moist carbonic acid gas on granite, as exemplified in the volcanic districts of Auvergne. Basaltic rocks were likewise prone to decomposition, partly in consequence of containing felspar, and partly from the protoxide of iron of the augite or hornblende which enters into their composition. The passage of the iron into a higher degree of oxidation was due to atmospheric oxygen applied in a liquid state to the rock through the medium of water. It was probable that carbonic acid likewise co-operated;-that, as in the rusting of iron, a carbonate of the protoxide was first generated, which subsequently passed into the hydrated peroxide of iron.

The rocks in which these changes occurred, underwent a total alteration both in their mechanical state and in chemical constitution. Their tenacity was so entirely destroyed, that the slightest force, a shower or the breeze, sufficed to overcome the cohesion of their particles. The alkali of the felspar was entirely washed away, and an earthy mixture, combined with water, remained. The ochreous tint of decomposed basalt and greenstone sufficiently indicated that their iron had passed into a higher state of oxidation; but felspar often left a perfectly white earth, the small portions of iron and manganese contained in the original rock having been removed, probably in the state of carbonate, during the progress of disintegration. These changes constituted one of the great sources of the alkalies present in springs and in the soil; and the alkaline matter of the nitrates of potash and soda, generated so abundantly in parts of India and America, had probably the same origin. They likewise accounted for the connexion observed between the agricultural character of the soil of certain districts, and the rocks from which it was derived. The decomposition of granitic rocks led to deposites of clay and sand, which were too entirely free from each other and from lime to be suitable for the growth of plants; while the earth derived from most basaltic rocks was an intimate mixture of argillaceous, siliceous, and calcareous matter, in proportions peculiarly favourable to vegetation.

II. Deposites from Aqueous Solution of Substances commonly considered insoluble.--The lecturer next discussed the second branch of his subject, referring more especially to siliceous depositions; such as flint, calcedony, and rock crystal. Many circumstances, he remarked, proved the fact that silica very frequently existed in solution. Mineral waters, he said, commonly contained silica:-chemists, indeed, frequently overlooked it in their analyses; but when carefully sought for, it might in most instances be detected. It was constantly con- 
tained in the sap of certain plants, if not in all. For it was shown by the late Sir H. Davy that silex is contained in grass, and in the epidermis of reeds, corn, canes, and of hollow plants in general. The existence of silex in the sap of the bamboo was not only attested by its flinty epidermis, but by the siliceous concretions called tabasheer: Similar evidence was afforded by some fossils, which contained silex in such a form as to indicate that it was deposited from a solution. In proof of his position the lecturer exhibited samples of shells having their form preserved in silex, some beautiful specimens of silicified coral, and a suite of chalk flints which displayed the structure of sponges and other zoophytes. For the opportunity of exhibiting such specimens he was indebted to the indulgence of the President and Council of the Geological Suciety. Traces of organization might by careful examination be so frequently detected in chalk flints, that he was disposed to the opinion of those geologists who considered flints in general as zoophytes fossilized by silica. The lecturer next adverted to the formation of calcedony, and showed specimens which, though found in igneous rocks, had their aqueous origin clearly established by the stalactitic form which they possessed. Similar masses of calcedony existed in some flints, and passed into the substance of flint by insensible gradations. The hollow balls of crystals, called geodes, afforded similar testimony, by presenting both calcedony and rock crystal under circumstances indicative of pre-existing solution.

The fact being established,- that siliceous minerals are frequently formed from aqueous solution, the lecturer went on to state the principles by which he thought the solution of siliceous matter, and its subsequent deposition, might be explained. The first observation he would make related to the meaning of the term insoluble. Chemists, he said, apply it to substances which are not found to lose an appreciable weight when subjected to the action of water. It was not affirmed that absolutely nothing was dissolved in such cases, but that the quantities were too small to be appreciated. This was true even of one of the most insoluble substances known to chemists; namely, sulphate of baryta. But though the weight of such bodies was not perceptibly diminished by trials conducted in the laboratory, during a short interval of time, and with small quantities of water, the effect of the same operation, as performed on the great scale in the mineral kingdom, during hundreds and thousands of years, and with unlimited quantities of the menstruum, might be, and doubtless was, very different. It was not necessary, however, to have re- 
course to this mode of reasoning. Substances, he said, which are inappreciably soluble in one state, may be freely dissolved in another. Silex in the finest powder may be boiled in water without perceptible solution; but if presented to that solvent while in the nascent state, it was freely dissolved. Substances in the act of being formed from their elements, or of separating from previously existing combinations, do not possess that force of aggregation which properly belongs to them, and in such states of transition they have a peculiar aptitude to combine with other bodies. This property is observed more or less in all bodies; but silica offers one of the most striking illustrations of it. Siliceous earth, in its nascent state, is freely soluble in water and in various acid and saline solutions, which do not perceptibly dissolve ordinary flint, however finely it may be pulverized ; and the alkalies and alkaline carbonates, which dissolve silex even in its solid condition, take it up while nascent in far greater quantity. Now in the decomposition of felspathic rocks, which had been referred to in the first part of the lecture expressly with a view to that subject, the silex was exposed to the united action of water and alkali at the moment of passing from the state of combination which constitutes felspar, and would be expected to be freely dissolved. That it was so, might be proved by a comparative view of the constitution of porcelain clay and felspar. He would represent their composition, he said, by a formula expressive of the number of equivalents of each element; though in doing so, he did not mean to assert that porcelain clay was strictly an atomic compound. Thus,

$$
\begin{array}{cc}
\text { Felspar. } & \text { Porcelain Clay. } \\
(\dot{\mathrm{P}} \mathrm{o}+3 \dot{\mathrm{Si}})+(\underline{\ddot{A} l}+9 \dot{\mathrm{Si}}) ; & \left(\underline{\ddot{\mathrm{l}}}+3 \frac{1}{2} \dot{\mathrm{Si}}\right) .
\end{array}
$$

The lecturer stated that the porcelain clay referred to, was a sample from Villarica, which he had analysed during the course of the winter. Besides aluminous and siliceous earth, it contained 21.3 per cent. of water. Mr. Rogers of Philadelphia had obligingly analysed for him some porcelain clay from the vicinity of Mont Dor in Auvergne, which had a similar constitution. Berthier and Rose had likewise analysed porcelain clay from other localities, and each found the ratio of the two earths to be nearly 2 equivalents of alumina to 3 of silica. Its constitution accordingly appeared subject to very slight variation. The formulæ showed that every 2 equivalents of alumina, present in porcelain clay along with $3 \frac{1}{2}$ of silica, corresponded in the original felspar, from which it was derived, to 12 equivalents of silica and 1 of potash. Third. Series. Vol. 3. No. 13. July 1833. 
Hence the quantity of silica carried off in solution was enormous.

The lecturer then went on to explain how it happened that silica, existing in solution, was deposited so as to constitute minerals. One obvious principle, he stated, was the molecular attraction which exists between similar particles of matter, as was proved by facts without number. Its existence was attested by the globular form assumed by water, oil, mercury, and other liquids;-by the separation from one another of salts in crystallizing out of mixed solutions;--by the formation of crystals during the slow deposition of vapour, as when camphor was subliming slowly in a glass bottle, the particles attaching themselves to one another rather than spreading uniformly over the surface on which they collect;-and by the tendency of like molecules to get together and cohere while intermixed with a mass of dissimilar matter rendered liquid by heat, as when particles of titanium, diffused in a furnace through a mass of iron, seek out each other and form regular crystals, or when minerals crystallize out of melted lava or basalt. So from solutions of silex, whether strong or dilute, the particles are disposed to adhere together whenever they cease to remain in solution.

Another principle applicable to this question, was the following: Whenever substances, insoluble in their ordinary state, were dissolved by the force of favourable circumstances, such solutions were very prone to decomposition. They formed instances of peculiarly unstable equilibrium. The slightest disturbing causes, - as agitation, change of temperature, or the affinity, though slight, of some other body for the solvent, - would in such cases put an end to the solution. Illustrative examples of this principle were afforded .by solutions of tin, titanium, and peroxide of iron in a neutral state. He might probably quote albuminous solutions as an instance from the animal kingdom. Water cooled carefully below its usual point of congelation, and saturated solutions of Glauber's salt, were liquids in which a similar instability of equilibrium was conspicuous. The lecturer, in illustration, here showed two solutions of Glauber's salt:sphere on removing the cork, or the slightest agitation, often caused such solutions to become solid; and that when these failed, the introduction of a solid body, especially a crystal of Glauber's salt, or of any substance having even a feeble affinity for the salt or its solvent, - such as a globule of air or carbonic acid gas, - generally determined immediate crystallization. The solutions on the lecture-table retained their form after removal 
of the cork and after gentle agitation: one of them instantly became solid on the introduction of a glass tube; and the other bore the introduction of the tube, but crystallized instantly when a globule of air from the lungs was blown through the tube. The principle elucidated by these facts was, he siid, directly applicable to his argument. A solution of silica oozing slowly into the cavities of a porous or cellular rock, might yield a deposite as a consequence of evaporation, of a slight affinity between the silica and some substance with which it accidentally came into contact, or of the solvent power of an alkali which had contributed to its solution being lessened by passing from the state of a simple carbonate to that of a bicarbonate, or by entering into some other mode of combination. The siliceous matter, being once solid, would most probably be insoluble in the menstruum by which it had been originally dissolved, and in that state would promote the increase of the deposite by its molecular attraction for the silex still remaining in solution. In this manner might cavities of considerable size be gradually filled up with calcedony, flint, or rock crystal. It was difficult, he said, to indicate the precise circumstances which determined the form assumed by the silex; but it was probable, agreeably to the laws of crystallization, that the development of regular crystals was owing to the extremely slow progress of the same process which, when less slow, might cause the deposite to be amorphous. In the formation of calcedony and flint it was most likely, as Brongniart supposed, that the silica, as in operations in the laboratory, was deposited in a gelatinous form, hardening gradually by evaporation and the cohesive attraction of its particles. The regularly disposed lines which were so beautifully displayed in some varieties of calcedony, seemed owing to successive deposition,-one layer succeeding another, each assuming the form and irregularities of the preceding, and differing in tint according to the absence or presence of small varying quantities of foreign matter, such as iron and manganese. In the case of flint it was necessary, he said, to account for that remarkable tendency which silica possessed, to occupy the place of organic matter, as exemplified by the specimens of flint,silicified wood, and coral, on the lecture-table. This phænomenon the lecturer thought might be explained on the principles which had been developed that evening. Siliceous solutions, infiltrating through organic masses in progress of decay, might readily be decomposed by the affinity of gases or other compounds generated during slow putrefaction, either for the silica itself, or for its solvent. In either case a deposite of silex would result. Consistently with this view, it was well known that E 2 
flints contained traces of bitumen or some similar substance of organic origin. To it the dark colour of flints was owing, and to its destruction the whiteness of roasted and bleached flints was attributable.

The lecturer, in conclusion, briefly referred to the formation of some other minerals. He explained that the production of crystals of selenite, celestine, and heavy spar, obviously resulted in many cases from the sulphuric acid arising, one while from burned sulphur in volcanic districts, and at another from oxidizing pyrites, acting upon contiguous masses containing lime, strontia, and baryta. He showed a specimen of red oxide of iron possessed of a stalactitic form decisive of aqueous origin; and oxide of manganese, he said, sometimes occurred in a similar state. He considered such specimens to have been originally deposited in the state of carbonates, out of solutions of carbonic acid, and to have been subsequently still further oxidized,-a change which he illustrated by a specimen of carbonate of manganese kindly given to him by Mr. Phillips, in which the progress of conversion was distinctly exhibited. He also suggested a possible explanation of the origin of the pyrites so often found in fossil shells imbedded in clay which abounds in nodular pyrites. It had been observed that sulphates undergo gradual deconposition by the action of organic matter; and he thought it therefore far from improbable that sulphate of iron, generated from oxidized pyrites, might by the deoxidizing agency of animal remains be reconverted into sulphuret.

VIII. Contributions to the Geology of Northumberland and Durham. By N.J. WINCH, Esq. G.S.\& A.L.S.*

MINERS and geologists at all conversant with the great II coal-field of Northumberland and Durham, are acquainted with the vein generally called the Main or Ninety-fathom Dyke, which traverses the district in a south-westerly direction, dividing it into two unequal portions, and which is only recurred to here as a guide to the situations of the coal mines whose sections form the subject, and are the chief value, of the following paper. This dyke may be seen to advantage both in the cliffs and intersecting the rocks on the sea-shore a little to the north of Cullercoates, from whence it passes by Whitley Quarry to Earsdon, Backworth, Killingworth, Gosforth, Denton Hall ; by the north corner of the field east of West Den-

* Communicated by the Author. ['The reader of these contributions should consult the map of Northumberland and Durham, in the First Series of the Transactions of the Geological Society, vol. iv. Plate I.-AUTHor.] 